\title{
Incisional hernia after upper abdominal surgery: a randomised controlled trial of midline versus transverse incision
}

\author{
J. A. Halm • H. Lip · P. I. Schmitz $\cdot$ J. Jeekel
}

Received: 17 August 2008 / Accepted: 12 December 2008 / Published online: 4 March 2009

(C) The Author(s) 2009. This article is published with open access at Springerlink.com

\begin{abstract}
Objectives To determine whether a transverse incision is an alternative to a midline incision in terms of incisional hernia incidence, surgical site infection, postoperative pain, hospital stay and cosmetics in cholecystectomy.

Summary background data Incisional hernias after midline incision are commonly underestimated but probably complicate between 2 and $20 \%$ of all abdominal wall closures. The midline incision is the preferred incision for surgery of the upper abdomen despite evidence that alternatives, such as the lateral paramedian and transverse incision, exist and might reduce the rate of incisional hernia. A RCT was preformed in the pre-laparoscopic cholecystectomy era the data of which were never published.

Methods One hundred and fifty female patients were randomly allocated to cholecystectomy through midline or transverse incision. Early complications, the duration to discharge and the in-hospital use of analgesics was noted. Patients returned to the surgical outpatient clinic for evaluation
\end{abstract}

J. A. Halm · J. Jeekel

Department of General Surgery, Erasmus MC,

University Medical Center Rotterdam, Dr. Molewaterplein 40,

3015 GD Rotterdam, The Netherlands

H. Lip

Department of Anesthesiology,

Sophia Hospital, Zwolle, The Netherlands

P. I. Schmitz

Department of Trials and Statistics, Erasmus MC,

University Medical Center Rotterdam,

Groene Hilledijk 301, 3075 EA Rotterdam, The Netherlands

J. A. Halm ( $\square)$

Department of Surgery, Ikazia Hospital,

Montessoriweg 1, 3083 AN Rotterdam, The Netherlands

e-mail: jenshalm@hotmail.com of the cosmetic results of the scar and to evaluate possible complications such as fistula, wound dehiscence and incisional hernia after a minimum of 12 months follow-up.

Results Two percent (1/60) of patients that had undergone the procedure through a transverse incision presented with an incisional hernia as opposed to $14 \%$ (9/63) of patients from the midline incision group $(P=0.017)$. Transverse incisions were found to be significantly shorter than midline incisions and associated with more pleasing appearance. More patients having undergone a midline incision, reported pain on day one, two and three postoperatively than patients from the transverse group. The use of analgesics did not differ between the two groups.

Conclusions In light of our results a transverse incision should, if possible, be considered as the preferred incision in acute and elective surgery of the upper abdomen when laparoscopic surgery is not an option.

Keywords Cholecystectomy $\cdot$ Hernia abdominal · Abdominal wall

\section{Introduction}

The rate of incisional hernia after midline incision is commonly underestimated but probably lies between 2 and 20\% [1-5]. Thus, incisional hernia is a major postoperative problem. The treatment of incisional hernia is complicated by high rates of recurrences. Recently, in a randomised controlled trial published by Burger et al. [6], midline incisional hernia repair has been shown to be associated with a 10-year cumulative recurrence rate of 63 and $32 \%$ for suture and mesh repair, respectively.

The midline incision is the preferred incision for surgery of the upper abdomen, despite evidence that alternatives, such as 
the lateral paramedian and transverse incision, exist and might reduce the rate of incisional hernia [7]. Various approaches to opening the abdomen have been advocated over time. The choice for a certain incision is dependent on the exposure necessary for the desired procedure to succeed. A midline incision, be it supraumbilical, infraumbilical or both, is an approach especially suited for emergency and exploratory surgery because of the quick and generous exposure that can be achieved within a few minutes $[8,9]$. The avascular nature of the linea alba minimises blood loss during this procedure. A supraumbilical transverse incision may be utilised in case exposure of the upper abdomen is desired. During this incision, the damage inflicted to the segmental arteries and nerves is previously described as being minimal [10]. Previously, only one randomised controlled trial, comparing transverse and true midline incisions, has been published specifically addressing incisional hernia incidence [11].

To determine whether the use of a transverse incision is an alternative to a midline incision for open cholecystectomy in terms of incisional hernia incidence, surgical site infection, postoperative pain and hospital stay, this randomised controlled trial was performed. This trial was conducted in an era when laparoscopic cholecystectomy was not yet available. The possibility of low incisional hernia rates after transverse incisions and the fact that little is known about potential advantages incited us to publish the relevant results of this randomised controlled trial which has been performed in the past and has only been reported in a Dutch thesis by one of the authors (H.L.). The primary endpoint of this study was the incisional hernia incidence after 12 months of follow-up. Secondary endpoints included pain and cosmetic appearance.

\section{Methods}

Protocol

Some 150 consecutive female patients were randomly assigned to a midline or transverse incision as an approach for elective cholecystectomy or combined cholecystectomy and cholangiography (with or without consecutive choledochotomy) (75 and 75 patients, respectively). Emergency procedures were excluded from participation. The sample size is based on an incisional hernia rate reduction from 20 to $6 \%$ at a power of $80 \%$ and an error rate of $5 \%$.

Obtaining informed consent was conducted in accordance with the ethical standards of the Helsinki Declaration of 1975. The investigation reported was performed with informed consent from all of the patients and followed the guidelines for experimental investigation with human subjects and was approved by the medical ethics committee. An independent statistician prepared closed, tamper-proof envelopes containing the random allocation (Fig. 1). Patients were randomised for one of the procedures in theatre through the opening of the envelopes.

Patient-related factors that were recorded were age, body mass and length and date of operation. Operation-related factors that were recorded were the exact nature of the operation, length of the incision, the thickness of the subcutaneous fat, surgeon performing the procedure, as well as the duration of the operation (skin-to-skin time). In the immediate postoperative period, the use, dose and type of analgesics was recorded and a pain score was administered. The use of analgesics (morphine $7.5 \mathrm{mg}$ intra-muscular injection, $4 \mathrm{~h}$ minimum interval between consecutive injections)
Fig. 1 Flow chart of patient inclusion and follow-up

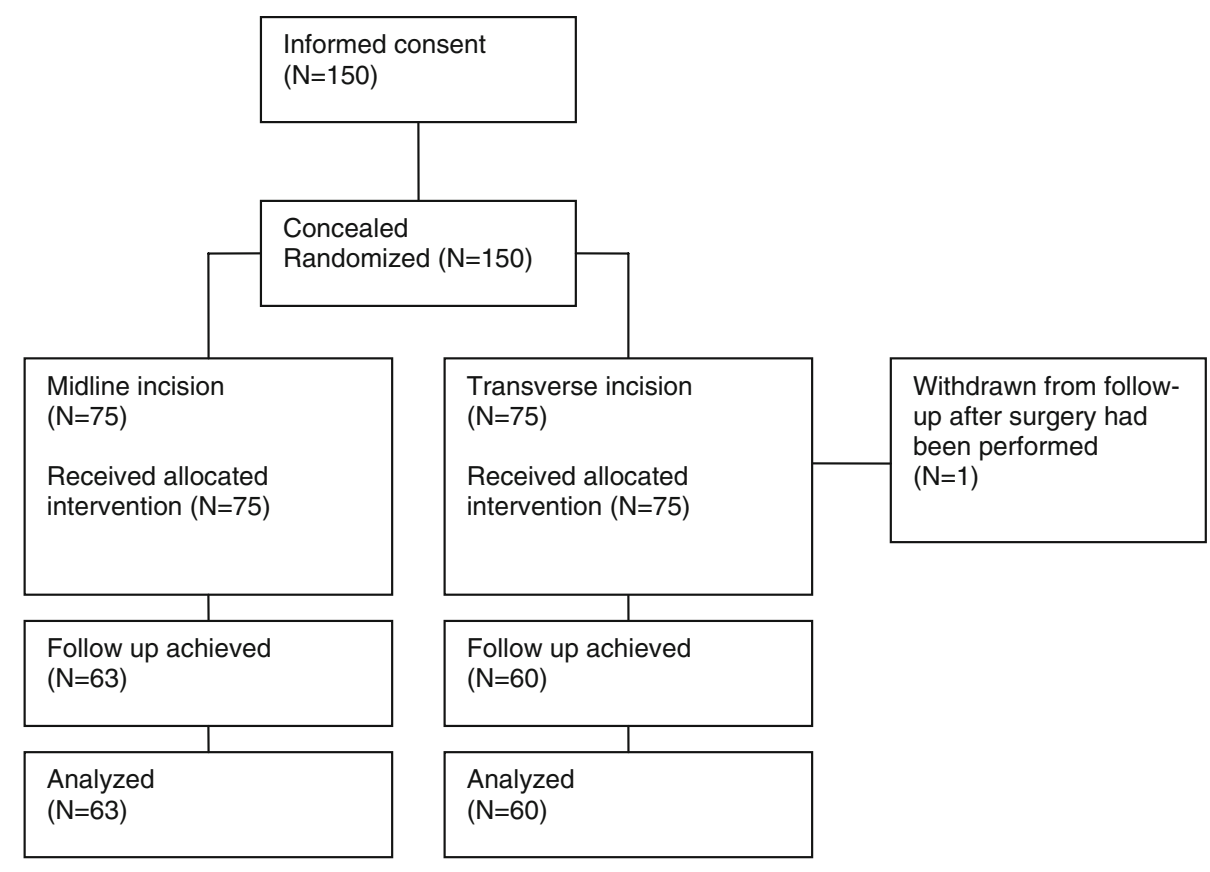


was monitored for $48 \mathrm{~h}$ after surgery; the pain score was administered for the first 6 days after surgery.

In patients assigned to surgery through a midline incision, the skin was incised from just below the xyphoid process to just above the umbilicus. The abdominal wall was opened in the midline by incising the linea alba. A Collin type (two-bladed) self-retaining retractor was used to maintain exposure. The abdominal wall was closed in one layer using single polygalactin 910 sutures (Vicryl; Ethicon, Amersfoort, The Netherlands). The skin was consequently closed using running monofilament nylon sutures (Ethilon; Ethicon, Amersfoort, The Netherlands).

Patients randomised for a transverse incision received a right-sided unilateral transverse incision between 3 and $4 \mathrm{~cm}$ below the costal margin. The rectus muscle was incised. The fibres of the external and internal obliques and the transverse muscles were separated in the direction of their course. Exposure was achieved through the use of a manually held single-bladed retractor. Closure of the abdominal wall was achieved by closure of the peritoneum and the posterior rectus fascia using a continuous, polygalactin 910 suture (Vicryl; Ethicon, Amersfoort, The Netherlands). The anterior rectus sheath and the fascia of the internal and external transverses were closed using simple interrupted polygalactin 910 sutures (Vicryl; Ethicon, Amersfoort, The Netherlands). Towards the end of both procedures, a Redon low-vacuum drain catheter was placed, which was guided outside the abdominal cavity approximately $5 \mathrm{~cm}$ from the incision. The skin was consequently closed using continuous monofilament nylon suture (Ethilon; Ethicon, Amersfoort, The Netherlands). All patients received a dose of 5,000 IU of sodium-heparin on the morning of the procedure as thrombosis prophylaxis.

\section{Statistical analysis}

The Pearson $\chi^{2}$ test was used for comparing percentages. In case of small expected numbers, a Fisher's exact test was performed. Continuous variables were analysed using the Mann-Whitney test. A $P$-value of 0.05 or less (two-sided) was considered to be statistically significant. Means and medians are expressed \pm standard deviation (SD).

Follow-up

Patients returned to the surgical outpatient clinic for evaluation of the cosmetic results of the scar and to evaluate possible complications, such as fistula, wound dehiscence and incisional hernia, after a minimum of 12 months follow-up. The patient and the surgeon evaluated the cosmetic results independently and were asked to rate the scar as unsatisfactory, satisfactory or fine. Furthermore, the length and width of the scar was measured.

\section{Results}

Study group

Some 150 consecutive patients were randomised for participation in this study during an inclusion period from April 1977 until July 1979. Seventy-five patients received a transverse incision and 75 patients a midline incision (Fig. 1).

One patient was withdrawn from further follow-up after developing peritonitis and consequent acute respiratory distress syndrome (ARDS) not related to the closure of the abdominal wall 2 days after surgery (transverse incision group).

The patients' average age was 51.9 and 51.4 years for the midline and the transverse incision groups, respectively. Furthermore, no differences were found in the body mass and average length between the two groups (Table 1). A cholecystectomy was performed using a transverse incision in 52 patients and utilising a midline incision in 52 patients also. Fifteen and 16 patients, respectively, underwent a combined cholangiography/cholecystectomy. A further 7 and 6 patients, respectively, were treated with a cholangiography/cholecystectomy plus additional choledochotomy and the postexploratory placement of a T-tube.

\section{Surgeon}

Staff surgeons performed $17 \%$ (13/75 patients) of all procedures performed through a midline incision. The remainder of the procedures through a midline incision was carried out under staff surgeon supervision. Staff surgeons performed $14 \%$ of all procedures in the transverse incisions study group (10/74 patients) and supervised the remainder. No statistically significant difference was found between the two randomised groups $(P=0.65)$.

\section{Duration of surgery}

No significant difference was noted in the skin-to-skin time (in min) for the two different incisions (Table 2). Surgery utilising midline and transverse incision took $56.9 \pm 29.3$ and $53.2 \pm 26.8 \mathrm{~min}$, respectively $(P=0.35)$. The total duration of the procedures until extubation (in $\mathrm{min}$ ) did not

Table 1 Baseline characteristics of the patients undergoing surgery, according to study group

\begin{tabular}{lll}
\hline Variable & Midline incision & Transverse incision \\
& $n=75$ & $n=74$ \\
\hline Average age (years) \pm SD & $51.9 \pm 14.8$ & $51.4 \pm 13.8$ \\
Average weight $(\mathrm{kg}) \pm \mathrm{SD}$ & $71.3 \pm 14.5$ & $68 \pm 14.3$ \\
Average length $(\mathrm{cm}) \pm \mathrm{SD}$ & $163.5 \pm 7.8$ & $164 \pm 7.3$ \\
\hline
\end{tabular}


Table 2 Length of incision, thickness of subcutaneous fat and skin-toskin time, according to study group

\begin{tabular}{|c|c|c|c|}
\hline Variable & $\begin{array}{l}\text { Midline } \\
\text { incision }\end{array}$ & $\begin{array}{l}\text { Transverse } \\
\text { incision }\end{array}$ & $P$-value \\
\hline $\begin{array}{l}\text { Length of incision } \\
\quad(\mathrm{mm}) \pm \mathrm{SD}^{\mathrm{a}}\end{array}$ & $164 \pm 28$ & $140 \pm 24$ & $<0.0001$ \\
\hline $\begin{array}{l}\text { Thickness of subcutaneous } \\
\text { fat }(\mathrm{mm}) \pm \mathrm{SD}^{\mathrm{a}}\end{array}$ & $34.5 \pm 13.0$ & $30.3 \pm 12.4$ & 0.05 \\
\hline $\begin{array}{l}\text { Skin-to-skin time } \\
\quad(\min ) \pm \mathrm{SD}^{\mathrm{a}}\end{array}$ & $56.9 \pm 29.3$ & $53.2 \pm 26.8$ & 0.40 \\
\hline $\begin{array}{l}\text { Width of scar } \\
\qquad(\mathrm{mm}) \pm \mathrm{SD}^{\mathrm{b}}\end{array}$ & $8.3 \pm 1.4$ & $3.3 \pm 1.2$ & $<0.0001$ \\
\hline
\end{tabular}

Table 3 Postoperatively reported pain, according to study group, shown as the number of patients reporting pain at the time points indicated (percentage), with the remainder of patients reporting no pain

\begin{tabular}{lllc}
\hline $\begin{array}{l}\text { Time point } \\
\text { after surgery }\end{array}$ & $\begin{array}{l}\text { Midline incision } \\
n=75\end{array}$ & $\begin{array}{l}\text { Transverse incision } \\
n=74\end{array}$ & $P$-value \\
& $\begin{array}{l}\text { Patients reporting } \\
\text { pain, } n(\%)\end{array}$ & $\begin{array}{l}\text { Patients reporting } \\
\text { pain, } n(\%)\end{array}$ & \\
\hline 3-4 h & $68(91)$ & $60(81)$ & 0.09 \\
First day & $64(85)$ & $39(53)$ & $<0.0001$ \\
Second day & $57(76)$ & $23(31)$ & $<0.0001$ \\
Third day & $28(37)$ & $9(12)$ & $<0.0001$ \\
Fourth day & $5(7)$ & $3(4)$ & 0.72 \\
Fifth day & $0(0)$ & $1(1)$ & 0.50 \\
Sixth day & $0(0)$ & $1(1)$ & 0.50 \\
\hline
\end{tabular}

differ between the midline and transverse incisions $(71.0 \pm 30.5$ and $67.0 \pm 27.3$, respectively, $P=0.34)$.

Pain and analgesics

Significantly more patients, having undergone a midline incision, reported pain on day one, two and three postoperatively $(P<0.0001$, Table 3$)$. In the midline incision group, $28 / 75$ patients required no or only one dose of analgesics; the remainder required two or more doses. Thirty-one patients operated through a transverse incision required no analgesics or only one dose; 43 patients (the remainder) required two or more. No significant difference in the use of analgesics was found between the groups $(P=0.69)$.

\section{Complications}

Postoperative complications (Table 4) were seen in 16 out of 75 patients $(21 \%)$ from the midline incision group and in $15 \%$ from the transverse incision group (11 patients)
Table 4 Rate of complications after surgery, according to study group, shown as the number of patients diagnosed with complications (percentage)

\begin{tabular}{llll}
\hline Complication & $\begin{array}{l}\text { Midline } \\
\text { incision }\end{array}$ & $\begin{array}{l}\text { Transverse } \\
\text { incision }\end{array}$ & $P$-value \\
& $n=75$ & $\begin{array}{l}n=75 \\
n(\%)\end{array}$ & \\
\hline Cardiac & $1(1)$ & $1(1)$ & 1 \\
Urinary retention & $8(12)$ & $6(8)$ & 0.59 \\
ARDS & 0 & $1(1)$ & 0.50 \\
Surgical site infection & $7(9)$ & $3(4)$ & 0.33 \\
Haemorrhage & $1(1)$ & 0 & 0.50 \\
Pneumonia & 0 & $1(1)$ & 0.50 \\
Total & $17(23)$ & $12(16)$ & 0.30 \\
\hline
\end{tabular}

$(P=0.30)$. Briefly, one patient in each group developed cardiac complications; 8 and 6 patients developed urinary retention after the midline and transverse incisions, respectively $(P=0.59)$. Surgical site infections were diagnosed in 7 and 3 patients, respectively $(P=0.33)$.

\section{Discharge}

Forty-five (60\%) and $42(57 \%)$ patients from the patients having undergone a midline or a transverse incision, respectively, were discharged on day 6 or 7 postoperatively. The remaining patients from each group left hospital care on day 8 or later. The duration of hospital admission did not differ between the two types of incision $(P=0.74)$.

\section{Cosmetics}

The width and length of all incisions was measured during the follow-up visit (Table 2). The mean width of the scar after the healing of the midline incisions was found to be $8.3 \pm 1.4 \mathrm{~mm}$. The mean width of the scar after the healing of the transverse incisions was measured to be $3.3 \pm 1.2$ $\mathrm{mm}$. This observed difference is significant $(P<0.0001)$. The length of the incisions was $140 \pm 24 \mathrm{~mm}$ and $164 \pm 28$ $\mathrm{mm}$ for the transverse and the midline incisions, respectively. The difference in scar length was found to be significant $(P<0.0001)$.

\section{Follow-up}

Eighty-one percent of all patients operated through a transverse incision were seen during the follow-up examination $(n=60)$. Of the patients operated through a midline incision, 63 out of 75 were seen at the outpatient clinic (84\%). The patients that were lost to follow-up could either not be traced or had deceased (Fig. 1). The minimum follow-up 
Table 5 Number of patients and surgeons rating the cosmetics of a scar at follow-up

Difference between type of incision: patients $P=0.03$; surgeons $P<0.0001$

\begin{tabular}{llllll}
\hline Score & \multicolumn{2}{l}{ Midline incision $(n=63)$} & & \multicolumn{2}{l}{ Transverse incision $(n=60)$} \\
\cline { 2 - 3 } & Patients, $n(\%)$ & Surgeons, $n(\%)$ & & Patients, $n(\%)$ & Surgeons, $n(\%)$ \\
\hline Unsatisfactory & $6(10)$ & $25(40)$ & & $2(3)$ & $6(10)$ \\
Satisfactory & $16(25)$ & $27(43)$ & & $9(15)$ & $12(20)$ \\
Fine & $41(65)$ & $11(17)$ & & $49(82)$ & $42(70)$ \\
Total & 63 & 63 & 60 & 60
\end{tabular}

for the evaluation of cosmetic results and hernia incidence was 12 months and the maximum was 36 months.

Incisional hernia

From the patients that had undergone the procedure through a transverse incision, one $(1 / 60 ; 2 \%)$ presented with an incisional hernia as opposed to 9 patients from the midline incision group $(9 / 63 ; 14 \%)$; $95 \%$ confidence interval (CI) 7.5-25.4\%. This difference in hernia incidence is significant $(P=0.017)$. No significant correlation was found between the incisional hernia rate and surgical site infection $(P=0.07)$.

\section{Subjective cosmetics}

Patients and surgeons alike were asked to rate the appearance of the scar during the postoperative follow-up outpatient clinic visit. Both the surgeons and the patients found the scar resulting from the transverse incision to be more cosmetically pleasing $(P<0.0001$ and $P=0.03$, respectively, Table 5).

\section{Discussion}

This prospective randomised study of transverse and midline incisions for open cholecystectomy shows that a significant reduction of incisional hernia incidence can be achieved through the use of a transverse incision.

Only one other study (published in 1980) reported the incidence of incisional hernia after upper abdominal midline and unilateral transverse incision in a randomised trial. No difference between the two techniques ( 8 and $6 \%$ incisional hernia, respectively) was found, but the relatively short follow-up of 6 months, however, may be held accountable for this finding [11]. Three retrospective studies showed rates of incisional hernia of 3.2, 5.4 and $16.5 \%$ for midline incision and 1.3, 6.7 and $13.4 \%$ for transverse incision without statistically significant differences [12-14].

The possible reason for the rather high incidence of incisional hernia in the midline incision group (14\%) may lie in the use of resorbable 910 polygalactin sutures. Nevertheless, the use of the same type of resorbable suture in the closure of the transverse incisions resulted in a $2 \%$ hernia rate. There is evidence for the importance of proper technique and choice of incision as a means to reduce incisional hernia being more important than the use of suture material [7]. Furthermore, as mentioned above, it is known that the incidence of incisional hernia in the case of a midline incision lies between 2 and 20\%. From our data, the NNT (numbers needed to treat) is calculated to be 8 (95\% CI 5-30) and the RRR (relative risk reduction) is $88 \%$ (95\% CI 23-100\%). Luijendijk et al. [15] have published a hernia rate of $2 \%$ after Pfannenstiel incisions closed using 910 polygalactin, which is in agreement with our findings in the patients randomised for a transverse incision, emphasising the importance of the incision over the choice of suture material.

In our study, significantly fewer patients reported pain on day 1, 2 and 3 after transverse incisions, a result that was also described by other authors [16, 17]. Greenall et al. [18] published a contradictory report (in 1980) in which no significant difference in postoperative pain was found between midline and transverse incisions. The previously mentioned study, however, only analysed 46 out of 572 patients $(8 \%)$ with regard to pain, which may explain the finding. In the same way, Lacy et al. suspended visual analogue pain scoring in a study comparing midline and transverse incisions for abdominal aortic surgery. Remarkably, the two groups in our study did not differ in terms of postoperative analgesia, a finding that is also reported by Lindgren et al. [17] and Donati et al. [19].

In our study, surgeons as well as patients were significantly more satisfied with the aesthetic appearance after a transverse in comparison with a midline incision. The scars after transverse incisions were found to be significantly shorter and less wide than the midline incisions, which may account for the observed difference. A possible reason for this is that a transverse incision is executed parallel to the prevailing direction of the skin lines on the abdomen and, therefore, the tension on the wound and consequent scar is low.

Cholecystectomy has come a long way since this trial. The introduction and widespread acceptance of laparoscopic technique as the treatment of choice has rendered open cholecystectomy to be an operation for exceptional, 
and perhaps surgically difficult, circumstances. Nowadays, the study reported is hardly feasible, yet, the results are still applicable and very relevant for other surgical procedures in the (upper) abdomen. Knowledge of the favourable results of a transverse incision may aid surgeons in their choice when finding themselves in the unfortunate position of needing conversion to open cholecystectomy.

In conclusion, this investigation on transverse incisions might be helpful in reducing the incidence of incisional hernia in patients after open cholecystectomy.

The midline incision is a preferred manner to achieve exposure of the abdominal cavity and is considered to be easily performed and quick. Although the midline incision is generally accepted, the incidence of incisional hernias is surprisingly high [1-5]. The choice for a particular incision should not only be based on exposure, but also on hernia incidence reduction, especially since recurrence rates after hernia repair are reported to be very high. Furthermore, the recurrence rate after incisional hernia repair is a disappointing 63 and 32\% for suture and mesh repair, respectively [6]. In the light of these results, incisional hernia prevention is warranted.

In this investigation, it is shown that a significant reduction (from 14.5 to $1.7 \%$ ) of incisional hernia incidence was achieved by using a transverse incision. Hence, a transverse incision should be considered as the preferred incision in acute and elective surgery of the upper abdomen in which laparoscopic surgery is not an option. Full exposure of two quadrants is feasible through the use of a unilateral transverse incision in, for example, biliary, bariatric, liver and colonic surgery. The transverse incision should be part of the abdominal surgeon's armamentarium and is a preferable incision to prevent the high incidence of incisional hernia after abdominal surgery.

Acknowledgments The authors wish to thank all of the surgeons who participated in the investigation and the patients included for the purpose of this study (the former "Sophia" Hospital, Zwolle, The Netherlands, which is now part of the "Isala Klinieken").

Open Access This article is distributed under the terms of the Creative Commons Attribution Noncommercial License which permits any noncommercial use, distribution, and reproduction in any medium, provided the original author(s) and source are credited.

\section{References}

1. Mudge M, Hughes LE (1985) Incisional hernia: a 10 year prospective study of incidence and attitudes. Br J Surg 72(1):70-71
2. Lewis RT, Wiegand FM (1989) Natural history of vertical abdominal parietal closure: Prolene versus Dexon. Can J Surg 32(3):196-200

3. Sugerman HJ, Kellum JM Jr, Reines HD, DeMaria EJ, Newsome HH, Lowry JW (1996) Greater risk of incisional hernia with morbidly obese than steroid-dependent patients and low recurrence with prefascial polypropylene mesh. Am J Surg 171(1):80-84

4. Hodgson NC, Malthaner RA, Ostbye T (2000) The search for an ideal method of abdominal fascial closure: a meta-analysis. Ann Surg 231(3):436-442

5. Höer J, Lawong G, Klinge U, Schumpelick V (2002) Factors influencing the development of incisional hernia. A retrospective study of 2,983 laparotomy patients over a period of 10 years. Chirurg 73(5):474-480

6. Burger JW, Luijendijk RW, Hop WC, Halm JA, Verdaasdonk EG, Jeekel J (2004) Long-term follow-up of a randomized controlled trial of suture versus mesh repair of incisional hernia. Ann Surg 240(4):578-583; discussion 583-585

7. Burger JW, van 't Riet M, Jeekel J (2002) Abdominal incisions: techniques and postoperative complications. Scand J Surg 91(4):315-321

8. Inaba T, Okinaga K, Fukushima R, Inuma H, Ogihara T, Ogawa F, Iwasaki K, Tanaka M, Yamada H (2004) Prospective randomized study of two laparotomy incisions for gastrectomy: midline incision versus transverse incision. Gastric Cancer 7(3):167-171

9. Guillou PJ, Hall TJ, Donaldson DR, Broughton AC, Brennan TG (1980) Vertical abdominal incisions-a choice? Br J Surg 67(6):395-399

10. Nahai F, Brown RG, Vasconez LO (1976) Blood supply to the abdominal wall as related to planning abdominal incisions. Am Surg 42(9):691-695

11. Greenall MJ, Evans M, Pollock AV (1980) Midline or transverse laparotomy? A random controlled clinical trial. Part I: influence on healing. Br J Surg 67(3):188-190

12. Thompson JB, Maclean KF, Coller FA (1949) Role of the transverse abdominal incision and early ambulation in the reduction of postoperative complications. Arch Surg 59(6):1267-1277

13. Lord RS, Crozier JA, Snell J, Meek AC (1994) Transverse abdominal incisions compared with midline incisions for elective infrarenal aortic reconstruction: predisposition to incisional hernia in patients with increased intraoperative blood loss. J Vasc Surg 20(1):27-33

14. Johnson B, Sharp R, Thursby P (1995) Incisional hernias: incidence following abdominal aortic aneurysm repair. J Cardiovasc Surg (Torino) 36(5):487-490

15. Luijendijk RW, Jeekel J, Storm RK, Schutte PJ, Hop WC, Drogendijk AC, Huikeshoven FJ (1997) The low transverse Pfannenstiel incision and the prevalence of incisional hernia and nerve entrapment. Ann Surg 225(4):365-369

16. Armstrong PJ, Burgess RW (1990) Choice of incision and pain following gallbladder surgery. Br J Surg 77(7):746-748

17. Lindgren PG, Nordgren SR, Oresland T, Hultén L (2001) Midline or transverse abdominal incision for right-sided colon cancer-a randomized trial. Colorectal Dis 3(1):46-50

18. Greenall MJ, Evans M, Pollock AV (1980) Midline or transverse laparotomy? A random controlled clinical trial. Part II: influence on postoperative pulmonary complications. Br J Surg 67(3):191-194

19. Donati D, Brown SR, Eu KW, Ho YH, Seow-Choen F (2002) Comparison between midline incision and limited right skin crease incision for right-sided colonic cancers. Tech Coloproctol 6(1):1-4 